\title{
El cuerpo en/del arte: la experiencia de lo éxtimo
}

\section{The Body in/of Art: the Experience of Extimacy}

\author{
Begonya SAEZ TAJAFUERCE \\ Universitat Autònoma de Barcelona \\ begonya.saez@uab.cat \\ Ana Cecilia GonZÁleZ \\ Universitat Autònoma de Barcelona \\ anaceciliagonzalezr@gmail.com
}

Recibido: 27/06/2013

Aceptado: 30/05/2014

\section{Resumen}

El objetivo de este artículo consiste en poner en diálogo la alteración constitutiva de la experiencia del arte para la que media el cuerpo, que cobra la forma de la impropiedad, según Nancy, con una categoría del corpus lacaniano que alude al orden de lo real, orden excluido tanto del orden imaginario como del orden simbólico y que comporta, por ello, un quiebre de la representación. Se trata de la categoría de lo éxtimo, que Lacan plantea en el Seminario VII (La ética del psicoanálisis), que alude a un desplazamiento del núcleo de articulación del sentido fuera del orden simbólico-imaginario, y que da lugar a la experiencia de un hiato constitutivo en/de la identidad que ningún proceso de identificación, léase representación, consigue clausurar.

Palabras clave: cuerpo, arte, representación, ejemplar, éxtimo, Nancy, Lacan, Lascaux

\begin{abstract}
The goal of this paper is to set the constitutive alteration impinged by the body in the experience of art, which according to Nancy thereby turns improper, in the light of a lacanian category that by means of the body makes evident the order of the real as excluded from the imaginary and the symbolic, and which therefore breaks representation down. This is the category of Extimacy, which Lacan raises in Seminar VII (The Ethics of Psychoanalysis), when referring to the displacement undergone by the core of articulated meaning outside the symbolic-imaginary order, which opens up for the experience of a constitutive hiatus in/of identity that no process of identification, i.e. representation, might close down.
\end{abstract}


Keywords: body, art, representation, exemplary, extimacy, Nancy, Lacan, Lascaux

“[E]l ahí es siempre una gruta” (2008: 103)

En el artículo "Pintura en la gruta", que, dicho sea de paso, en su versión original en francés lleva el subtítulo: "Sobre las paredes rocosas de G. [eorge] B. [ataille]", J.-L. Nancy afirma ya en la entrada: "El hombre comenzó por la extrañeza de su propia humanidad. O por la humanidad de su propia extrañeza. Se presentó en ella: se la

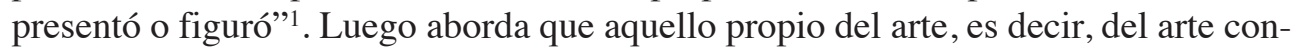
cebido como mostración de la que por otra parte hace alarde el así bautizado por Nancy homo monstrans, consiste en la presentación y/o figuración de sí del ser humano de su propia extrañeza de sí como ser humano, es decir, de la extrañeza de su humanidad. Y, de ahí, el arte consiste en la presentación y/o figuración de la absoluta impropiedad de dicha humanidad. $\mathrm{O}$, dicho de otro modo, el arte consiste en la presentación y/o figuración de su absoluta monstruosidad, es decir, de la absoluta impropiedad de aquello que le es más propio al ser humano y que, sin embargo, deviene sólo entonces, es decir, en virtud de dicha extrañeza o impropiedad, propio. He aquí la paradoja constitutiva al/del arte.

En la entrada, entonces, no se muestra la identidad, sino la extrañeza. En la entrada, se muestra la extraña presencia ante sí. Esa experiencia redoblada de extrañeza -considerada como experiencia y como experiencia presente y/o figurada a la par que, sin embargo, en esa mostración, se ausenta- atraviesa al ser humano en verdad en todas sus prácticas, aunque, de manera ejemplar en su práctica artística. Y en esa práctica lo atraviesa de tal modo que adquiere estatuto ontológico, estético y político. Es así, en esa experiencia ejemplar de extrañeza, como el ser humano es expuesto: llevado a sí fuera de sí. En la experiencia del arte, el ser humano es expuesto en la gruta como exemplum.

Y dicha práctica artística encuentra su declinación primera en el cuerpo, aquí cuerpo del mundo, cuerpo de la gruta que, por ser siempre ya fuera de sí, en la obra de J.L. Nancy, saca a dicha práctica de sí. Como afirma en el mencionado artículo, en dicha práctica, el ser humano es penetrado por el secreto de la naturaleza "y él mismo expuesto como secreto" 2 en tanto que trazado, con el cuerpo del mundo, sobre la pared de una roca. El cuerpo de la roca es donde se experimenta la necesaria perturbación de la mímesis y se muestra esa "extrañeza reconocible" o un "reconocimiento que habría que llamar extrañado" y que ha de conformar el vínculo con lo que

\footnotetext{
${ }^{1}$ J. L. Nancy, Las Musas, Buenos Aires, Amorrortu, 2008, p. 101.

${ }^{2}$ Ibidem.

${ }^{3}$ Ibidem.
} 
venimos a llamar la experiencia de lo éxtimo para tomar el neologismo de Lacan.

En ese sentido, la experiencia del arte declinada desde el cuerpo, el cuerpo del mundo, el cuerpo de la gruta, remite a la presencia en su "extrañeza absoluta". O, como afirma Nancy en Noli me tangere. Ensayo sobre el levantamiento del cuerpo, remite a la "presencia que se sustrae a sí misma"4, en tanto y en cuanto aquello único que muestra y que puede ser mostrado es una ausencia.

Nos interesa aquí incidir en la perturbación de la mímesis, de la que hace reiterado tema Nancy, la cual comporta siempre ya una perturbación de la representación, en la medida en que ni la una ni la otra ofrece un modelo que llame a ser imitado, puesto que, como se ha visto, toda imitación se ve impedida. En cambio, ajena a toda mediación, la mímesis -y/o la representación- suscita una inteligibilidad otra que hace de la gruta una cavidad que se cierra sobre sí misma, un cuerpo enigmático con el que no cabe complicidad alguna, y mucho menos una complicidad que pueda brindar la opción de una identificación, a no ser que se trate de una identificación ya de entrada perturbada. Así, lo que muestra la gruta de la pintura en la gruta, la gruta tomada como exemplum; lo que muestra el exemplum en cuanto tal, entonces, no es sino la mera mostración como mero estar-fuera-de-sí, aunque cerrado sobre sí. En este ser y este darse paradójicos de la experiencia del arte, se hace evidente su falta de propósito, su falta de fin, su falta de mira; pues no hay propósito, ni fin, ni mira del exemplum fuera de la cancelación de todo propósito, de todo fin y de toda mira. Y en ese sentido, sólo en ese, es paradigmático el exemplum.

En ese sentido justamente, escribe Nancy al respecto de la pintura en la gruta:

"Reconozco en ello que soy irreconocible para mí mismo, y sin eso no habría reconocimiento alguno. Reconozco que eso constituye tanto un ser como un no-ser, y que yo soy uno en otro. Soy el ser-uno-en-otro. El mismo es el mismo sin volver jamás a sí, y de ese modo se identifica. El mismo es el mismo de una identidad que se altera desde el nacimiento, sedienta de que aún nunca ha sido sí, y cuyo nacimiento ya es alteración y se apropia como esa alteración misma"s.

Lo que se traza, entonces, de modo indefinido y ejemplar en la pared de la roca, no es ningún sentido concreto mejor o peor escondido en un símbolo que conviene descifrar con el fin de vencer la resistencia que supuestamente opone. Lo que se traza, en cambio,

"[e]s la huella de la extrañeza que viene como una intimidad abierta, experiencia más

\footnotetext{
${ }^{4}$ J. L. Nancy, Noli me tangere. Ensayo sobre el levantamiento del cuerpo, Madrid, Minima Trotta, 2006, pp. 47-48.

${ }^{5}$ J. L. Nancy, Las Musas, op. cit., pp. 101-102.
} 
interior que cualquier intimidad, hundida como la gruta, abierta como la aperturidad y la apariencia de su pared. La figura trazada es esa misma apertura, el espaciamiento mediante el cual el hombre llega al mundo y este mismo es un mundo: el acontecimiento de toda la presencia en su extrañeza absoluta"6.

La gruta no admite mediación, en efecto, y por eso en ella, como ella, "el mundo no tiene ni tiempo, ni lugar, ni sujeto" ", los cuales constituyen los puntos de referencia que permiten establecer las coordenadas que requiere toda identidad y/o identificación.

Es importante hacer hincapié en el hecho de que lo que se traza es una apertura, un espaciamiento. Pero, además, es relevante aquí considerar que la apertura y el espaciamiento que tienen lugar mediante el trazado en la pared de la roca tienen un carácter paradigmático, es decir, ejemplar. Pues lo que se traza en la pared de la roca y, con ello, en su cuerpo, tanto como en el cuerpo del mundo, no es un trazo cualquiera, pero tampoco es el trazo de eso otro que en el trazo se pudiera poner de manifiesto. Lo que se traza, en cambio, retomando la cita anterior de la pintura en la gruta, es esa "intimidad abierta [...] hundida como la gruta [...] mediante la cual el hombre

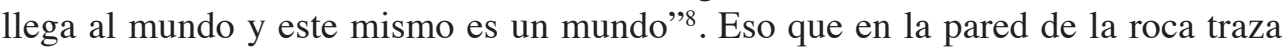
Nancy, esa "intimidad abierta", es lo que sin lugar a dudas dialoga con lo éxtimo propuesto por Lacan; y dialoga, además, en tanto en cuanto es un exemplum.

Pero, antes de adentrarnos en ese diálogo abierto entre la extrañeza de J. L. Nancy y la extimidad de Lacan al respecto de la experiencia del arte en la gruta, es preciso detenernos brevemente en la consideración del cuerpo de la gruta, del cuerpo del mundo y del cuerpo del arte desde un lugar que ya ha sido mencionado, a saber, el exemplum; pues, también en ese lugar, sin duda estructural, cabe suscitar el diálogo entre sendos planteamientos.

Por exemplum se da a entender aquí, en remisión a exemere, la extracción de un grupo de un particular a manera de muestra (o modelo). En el contexto de la gruta, tanto para Nancy como para Lacan, el exemplum sería lo que se ex-cava, lo que se saca fuera del lugar que le es propio, y, por tanto, también lo que deja hueco, lo que genera agujero, lo que constituye borde. Se trata del cuerpo-vasija-que remite, como veremos en detalle más adelante, a la Cosa heideggeriana ${ }^{9}$. Y cabe anticipar que es

\footnotetext{
${ }^{6}$ Ibidem, p. 101.

${ }^{7}$ Ibidem, p. 103.

${ }^{8}$ Ibidem, p. 102.

${ }^{9}$ Martin Heidegger pronuncia en diciembre de 1949 en Bremen la conferencia titulada Das Ding. El texto homónimo que acabó siendo publicado ("La cosa", Conferencias y artículos, Barcelona, Ediciones del Serbal, 1994) es el que toman como referencia para sendas elaboraciones tanto Nancy,quien, desde planteamientos diversos, se ocupa de "ese vacío que no colma", que es el modo en que lo denomina en Las Musas, también en Un pensamiento finito ("Un pensamiento finito") y en
} 
el cuerpo mismo de la gruta, del mundo y, a la par, el cuerpo del arte, el que se extrae a manera de muestra (o modelo) que, sin embargo, ciertamente de manera ejemplar, rehúsa dicho cargo. Y es que exemere, cual hueco excavado en sí mismo en cuanto lenguaje, es decir, en cuanto cuerpo semántico, remite a la vez a eximir, es decir, a excusar de cuidados, de obligaciones y de cargos. Se trata aquí del lenguaje exento de representar, o, mejor, del sentido exento de significar. En la gruta, escribe Nancy,

\begin{abstract}
"se trata [...] del silencio que deja sobrevenir la extrañeza del ser: su inmediata contigüidad en la pared misma. Ese silencio no hace nada: expone todo. Y no precede a la palabra ni la sucede: es su tensión, su vibración que no deja pesar ni postular significación alguna. Silencio de una humanidad sin frase (pero no sin habla), a la que nada relaciona con sus fines, a la que nada hace pasar por otra cosa que lo que es: la simple extrañeza de la presentación. (Una humanidad sin humanismo)"10.
\end{abstract}

La gruta, entonces, y, con ella, el mundo, expone su cuerpo a la experiencia del arte que la excava para eximirla de significación alguna, pues de ella no se extrae ningún sentido, y en esa exposición se perturba, de manera ejemplar y también inaugural, la mímesis. Afirma Nancy: "El sentido que es el mundo directamente en sí mismo, ese sentido inmanente de ser ahí y nada más, viene a mostrar su transcendencia: que consiste en no tener sentido [...] sino en presentarse siempre como su propio extrañamiento"11. Y dicha exposición lo es, ante todo, del devenir ontológico. Escribe Nancy al respecto: "Así, la pintura que comienza en las grutas [...] es en primer lugar la mostración del comienzo del ser, antes de ser el inicio de la pintura"12.

\footnotetext{
"Nacer a la presencia"-, como Lacan, quien le dedica una larga consideración en el seminario titulado La ética del psicoanálisis, impartido durante el curso 1959-1960 en el hospital de St. Anne, en París. Heidegger, tejiendo la trama del inquirir ontológico, se pregunta en ese texto por la cosidad de la Cosa, es decir, por la esencia de la Cosa en el sentido de eso en virtud de lo cual la Cosa es Cosa, y tienta la respuesta trayendo a colación una jarra (o vasija), tanto en lo relativo a su aspecto (materia y forma) cuanto a su función (causa y efecto), para llegar a concluir que nada de ello es lo que hace de la Cosa Cosa, pues, lo que hace de la jarra es el vacío en la medida en que "el vacío es lo que acoge del recipiente. El vacío, esta nada de la jarra, es lo que la jarra es como recipiente que acoge." Y, aún, Heidegger, tras resaltar la doble potencia de ese acoger (en tanto que tomar y retener), señala que "el doble acoger del vacío destaca en el verter hacia fuera", y añade: "a la coligación del doble acoger en dirección al verter hacia afuera, cuya conjunción, y sólo ella, es lo que constituye la plena esencia del escanciar (Schenken) (obsequiar), lo llamamos el obsequio (Geschenk)". Aunque de modo oblicuo, sin duda estas consideraciones de la jarra qua cuerpo-vasija en virtud del vacío y de la posibilidad que ese vacío sostiene, informan la reflexión en torno al cuerpo en/de la experiencia del arte qua cuerpo de la gruta tal como se ha venido articulando.

${ }^{10}$ J. L. Nancy, Las Musas, op. cit., p. 105.

${ }^{11}$ Ibidem, p. 103.

12 Ibidem, p. 102.
} 
Teniendo en cuenta estos elementos, nos preguntamos en qué medida cabe relacionar la experiencia del arte según Nancy con la estética de lo éxtimo según Lacan.

En el seminario titulado La ética del psicoanálisis ${ }^{13}$, Lacan centra buena parte de su exposición en la noción de das Ding, recogida del "proyecto" freudiano de $1895^{14}$ y reelaborada con ayuda del texto homónimo de Heidegger, ya antes mencionado, del que toma el soberbio ejemplo de la vasija de alfarería, que da lugar al consiguiente análisis de éste, de marcado alcance ontológico, que emplaza el Ser al doble modo del acogimiento y del don.

Con das Ding, en palabras de Lacan, "[s]e trata de ese interior excluido, que, para retomar los términos del Entwurf, está de este modo excluido en el interior"15. Lo real, en el sentido lacaniano del término, encuentra en das Ding una de sus primeras presentaciones, cobrando la (no) forma de "vacuola" o vacío en lo simbólico -en el que resuena sin duda "ese vacío que no colma" evocado por Nancy-. La "vacuola" de Lacan es el lugar de lo real en considerado como alteridad radical y de un goce absoluto, por siempre inalcanzable. La relación que todo sujeto guarda con esa "vacuola" le lleva a contornearla en la búsqueda de satisfacción, pero siempre procurando mantenerla a distancia, cubriéndola con velos, o "colonizando" su espacio con objetos imaginarios y señuelos. De ahí, de esa búsqueda incansable que convive con un eterno guardar distancia, la célebre fórmula que Lacan ofrece de la sublimación, según la cual ésta consiste en elevar un objeto a "la dignidad de la Cosa".

Lacan acuña el neologismo "éxtimo" para describir a das Ding, y, refiriéndose al trabajo de otra psicoanalista ${ }^{16}$ sobre la pintura rupestre en la cueva de Altamira, afirma: “[q]uizás lo que describimos como ese lugar central, esa exterioridad íntima, esa extimidad que es la Cosa, esclarecerá la pregunta que aún subsiste, el misterio incluso que representa para quienes se interesan en el arte prehistórico -a saber, precisamente su emplazamiento"17.

Lacan sugiere a raíz de ese comentario que la gruta que aloja el arte prehistórico y la Cosa guardan cierta relación de homología, o, al menos, que están concernidas por la misma condición ontológica que él denomina extimidad. El nexo entre el vacío de lo éxtimo y la creación lo encuentra Lacan en la vasija de Heidegger, a la que con-

\footnotetext{
${ }^{13}$ J. Lacan, El Seminario, Libro 7, La ética del psicoanálisis, Buenos Aires, Paidós, 2009.

${ }^{14}$ S. Freud, "Proyecto de una psicología para neurólogos", en Obras Completas, Tomo I, Buenos Aires, Amorrortu, 1993.

${ }^{15}$ J. Lacan, El Seminario, Libro 7, La ética del psicoanálisis, op. cit., p. 126.

${ }^{16}$ Lacan dialoga con Ella Sharpe y, en concreto, con relación a un artículo que ella escribió acerca de la sublimación, donde ella desea demostrar que la sublimación arraiga en la identificación primitiva a los padres. Ese y otros textos de la psicoanalista inglesa, que Lacan admiraba por su rigor y cuidado en la práctica clínica, se recogen en P. Brient, À propos de ... Ella Sharpe lue par Lacan, París, Éditions Hermann, 2007.

${ }^{17}$ J. Lacan, El Seminario, Libro 7, La ética del psicoanálisis, op. cit., p. 171.
} 
sidera paradigmática, es decir, exemplum, en tanto que objeto hecho para representar la existencia de "ese vacío en el centro de lo real que es la Cosa"18.

Luego la vasija es un significante que introduce de una vez lo vacío y lo pleno. Dicho de otro modo: en la representación se encuentra siempre ya contenido el vacío o agujero alrededor del cual la creación como tal tiene lugar, que, en consecuencia, es siempre creación ex nihilo. Lacan sugiere, por tanto, en torno al "misterio" de la pintura cavernaria, una ficción teórica acerca de los albores de la humanidad y los inicios de la actividad simbólica que permite dialogar con la propuesta de Nancy.

Así, mientras Lacan enfatiza la relación con el vacío cavado en lo real por el significante (o lo simbólico), Nancy postula la extrañeza como condición ontológica humanizante vinculándola con la práctica artística como presentación y/o figuración, en tanto que mostración, y ambas ideas se reúnen en la imagen excavada en/de la gruta pintada por el hombre paleolítico. Para Lacan " [...] hay identidad entre el modelamiento del significante y la introducción en lo real de una hiancia, de un agujero"19. Nancy, por su parte, sostiene que "[t]odo se da con ese pase de manos que traza el contorno de una presencia extraña" ${ }^{20}$.

"Bajo la tierra, como si tocara la ruptura de todo soporte y el fundamento de toda separación, el mundo entero salía a la superficie..."21.

Como hecha a medida, La cueva de los sueños olvidados, de Werner Herzog ${ }^{22}$, ofrece una ocasión excepcional para poner en relación la extimidad de la hiancia con la presencia en su "absoluta extrañeza".

La película es un documental que nos adentra en la Cueva de Chauvet, la "galería natural" de arte más antigua conocida, más antigua que Lascaux, referente de $\mathrm{Nancy}^{23}$, y más antigua que Altamira, referente de Lacan. Excavada en roca caliza,

\footnotetext{
${ }^{18}$ Ibidem, p. 152.

${ }^{19}$ Ibidem, p. 151.

${ }^{20}$ J. L. Nancy, Las Musas, op. cit., p. 101.

${ }^{21}$ Ibidem, p. 106.

${ }^{22}$ La cueva de los sueños olvidados es el título de la película-documental dirigida por Werner Herzog y presentada en 2010, en el Festival internacional de cine de Toronto. Herzog muestra en 3D el arte rupestre en la versión que de éste ofrece la cueva de Chauvet.

${ }^{23}$ La cueva de Lascaux es referencia expresa de Nancy en otro de los artículos recopilados en Las Musas, a saber, "El vestigio del arte", donde cita además al respecto del paso y la huella de los animales, "y de lo que en el hombre constituye vestigio animal", a Bataille y a su "bestia de Lascaux" en Lascaux o el nacimiento del arte, de 1955 (J. L. Nancy Las Musas, op. cit., p. 132). Para un estudio más detallado de la participación del texto de Bataille en sendos textos de Nancy, véase el artículo de Marcela Rivera Hutinel, "Jean-Luc Nancy: La pintura en la gruta, o el trazado del mundo”, en Archivos: Revista de Filosofía, n. 4-5, 2009-2010, pp. 185-203.
} 
Chauvet nos obsequia con más de 400 pinturas rupestres de unos 30.000 años. Descubierta en estado intacto en el sur de Francia en 1994 y preservada hasta este film de los ojos del público, la cueva es una perfecta "cápsula del tiempo", sellada hace 20.000 años, cuando una pared del acantilado sobre el que se sostiene se deslizó cerrando su boca de entrada. Ingresar en ella con el relato de Herzog es casi como volver a descubrirla, pues suscita la experiencia de la misma e (im)propia extrañeza contenida en el gesto figurativo de los autores de esas pinturas, hasta el punto en que, quien observa, vuelve a re-presentarse el vacío de lo real ${ }^{24}$, según Lacan, o a abrir la dimensión de presencia "ausentificada" constitutiva de lo humano, según Nancy. Vuelve, en fin, ya en la entrada, a hacer experiencia de la ejemplar perturbación de la mímesis.

Este no es el lugar para atender en detalle al relato de la película. Pero, sí juzgamos oportuno, justamente a modo de ejemplo, recuperar alguna de las escenas que ponen de manifiesto en qué medida la experiencia del arte, dada en/por el cuerpo de la cueva, es ofrecida en los términos planteados y contribuye a establecer un vínculo entre la propuesta de Nancy y la de Lacan para pensar la re-presentación como agujero y desde sus bordes; para excavarla.

Con este propósito, destacamos la escena en que el equipo de filmación, guiado por el científico responsable de las investigaciones en la cueva, que la custodia y la cura, es invitado por éste a guardar silencio y advierte que quizás escucharán latir su corazón, a la vez que enseña las primeras tomas de las pinturas y señala: "estas imágenes son recuerdos de sueños olvidados hace mucho tiempo". En ese preciso instante, la voz en off de Herzog pregunta: “¿[s]on sus corazones, los que laten, o son los nuestros?" (21'40). Ese quiebre en el relato, ajado mediante el coqueteo con una semejanza que ningún relato, ni siquiera científico, se vería capaz de establecer, se corresponde con la hiancia introducida en lo real, con el agujero que pone en evidencia el vacío como lugar primero de significación, en el trazo mismo al que se entrega pintor. Y, en ese trazo, "[1]a gruta es el mundo, donde el dibujo hace surgir lo imposible fuera del mundo, y lo hace surgir en su imposibilidad misma" 25 . Ese quiebre en el relato muestra el modo y el sentido en que el cuerpo de la gruta acoge y dona, "deja acaecer algo del ser interrumpido, de su extrañamiento" 26 . No podemos eludir aquí

\footnotetext{
${ }^{24}$ Concordamos en otorgar al vacío, en tanto que vacío de lo real, el lugar central de la estética de lo éxtimo en Lacan con Sergio Larriera en su artículo "Arte y Pensamiento", incluido en Lacan, Heidegger: el psicoanálisis en la tarea del pensar (J. Alemán y S. Larriera, Málaga, Miguel Gómez Ediciones, 1998, pp. 185-223). En ese sentido, afirma el autor que, "[e]n torno a un vacío esencial, el artista hace presente la Cosa dándole una pared simbólica" y, de ese modo, "la caverna [acaba] siendo una "organización significante alrededor de la extimidad del vacío" (J. Alemán y S. Larriera, op.cit., p. 199).

${ }^{25}$ J. L. Nancy, Las Musas, op. cit., p. 108.

${ }^{26}$ Ibidem, p. 107.
} 
que la alusión de Herzog a esa presencia ausente, cobra, más adelante en la película, como envolviéndola, un tinte que vira hacia la angustia.

Herzog dispone magistralmente una dilatada y no menos variada gama de recursos que apuntalan la experiencia de lo éxtimo. De entrada, apenas iniciada la película, entrevista a un joven arqueólogo, quien formula la verdad con estructura de ficción -al decir de Lacan- inherente al pretendido "documental": el objetivo de la investigación -y de la filmación, cabe agregar- de la cueva de Chauvet es crear historias sobre lo que pudo haber pasado en la cueva, porque "sólo podemos crear una re-presentación del pasado con lo que existe ahora". Es decir, una representación de la representación efectuada por el humano paleolítico. Treinta mil años después, con recursos tecnológicos más sofisticados, seguimos capturados en el régimen representativo, entendido como sistema ontológico propio de Occidente, según sostiene Nancy (en La representación prohibida ${ }^{27}$ ). Hacia el final de la película, alguien lo señala explícitamente: el Cromagnon, con la figuración, inventó un medio para decir del pasado, que se proyecta hacia el futuro indefinidamente, y esta invención es aún actual, como lo son las cámaras con que, de hecho, se está filmando. De este modo, en el final se completa el movimiento reflexivo de la estrategia narrativa de Herzog, fundada en la reiteración de una serie de elementos que ponen de relieve la iteración inherente a la estructura re-presentativa, es decir, el gesto de presentar una y otra vez, y otra y otra..., haciendo de lo mismo, otro, cada vez.

Ese mismo gesto cobra también la forma de un incesante vaivén que lleva al espectador ora dentro ora fuera de la gruta. La mirada del espectador parece retomar sin tregua el gesto excavador propio de la experiencia del arte y, retoma el cuerpo de la gruta mediante ese gesto que "difiere en cada ocasión y la traza nunca es una: siempre distinta de otra" 28 . Así, insiste Nancy "[a]trapado en esa postura, en medio de ese gesto, el primer pintor se ve, y el mundo con él, llegar a sí como aquel que nunca fue ni será, como el extranjero llegado de ninguna parte y destinado a ninguna parte, sin ir, entonces, ni venir" ${ }^{29}$. Herzog trae y lleva al espectador al dentro y al fuera de la gruta, también en la medida en que lo trae al dentro y fuera del relato científico, al dentro y fuera de la trama de la película, al dentro y fuera del tiempo del suceso, es decir, en la medida en que lo trae y lo lleva al dentro y al afuera de la representación; y lo instala en un ir y venir que no cesa sólo para saberse "únicamente puesto, separado, aislado en un trazo frente a sî"30; para saberse "ausente, tal cual está ausente el autor del mundo"; para saberse no ya en el agujero, sino en los bordes.

27 J. L. Nancy, La representación prohibida, Buenos Aires, Amorrortu, 2006.

${ }^{28}$ J. L. Nancy, Las Musas, op. cit., p. 109.

${ }^{29}$ Ibidem .

${ }^{30}$ Ibidem . 
Las imágenes son de una destreza y belleza que hablan por sí mismas, sólo hace falta extraer la conclusión que se impone y así lo enuncia Herzog: estas obras no hablan de un inicio primitivo o de una lenta evolución, sino de que el arte figurativo entró en escena de repente, como un evento explosivo, "como si el alma del hombre moderno se hubiera despertado aquí", concluye. Al final de la secuencia de pinturas, en la última recámara y sin que nada advierta del alcance del clímax, la curadora de la cueva señala una roca colgante en cuya parte baja hay pintado un pedazo de cuerpo femenino, sus piernas y su pubis, conectada por el otro lado de la roca con una cabeza de bisonte con brazo humano, un minotauro como el de Picasso, señala, un mito que ha durado más de treinta mil años. Herzog acusa el golpe: nos encontramos frente a la única representación (parcial) de un cuerpo humano en la cueva, "tan enigmática como la que gente que la hizo", dice. En este punto, sin duda, la experiencia de quiebre del relato y, así, de la experiencia de la gruta, del cuerpo en/del arte, resulta ejemplar, pues, además, por razones de preservación, en una primera toma no está permitido acceder a ese rincón, del que sólo tenemos una visión parcial, reforzando el enigma. En la experiencia del quiebre, sorteando el dentro-fuera en el borde, excavando, coinciden pintor y espectador. El uno, como el otro, "[s]e asombra, se preocupa y se ríe de esa postura y de lo que esta le muestra: la forma del animal, su propia forma y la del ser mismo, recortada frente a él, dejada como una huella que no lleva a otro lado que a la pared de la gruta y las soberbias imágenes"31.

Justamente de eso que la postura, de eso que el gesto propio de la experiencia del arte en/desde el cuerpo de la gruta muestra, pende una posible formulación de la estética de lo éxtimo según Lacan. Pues, de una parte, ese gesto "no muestra otra cosa que su manera de mostrarse, de configurar su ausencia de figura" 32 . Y también, de otra parte, porque eso que se muestra es eso que es y sólo puedo ser monstruo que "muestra de la semejanza que no se asemeja a nada"33.

Insistimos en que se trata de una formulación de la estética de lo éxtimo y no, por ejemplo, de la formulación de una estética de lo Unheimlich, término que ocupa a Lacan en su Seminario 10 - La angustia ${ }^{34}$ - y que recupera de un texto homónimo firmado por Freud. La experiencia de lo Unheimlich, que conviene traducir por "inquietante extrañeza", es una experiencia sin duda vecina de la experiencia de lo éxtimo. Lo Unheimlich, según la lectura que propone Lacan del texto freudiano, es precursor de la angustia, la cual se presenta cuando "falta la falta" es decir, cuando algo aparece en el lugar donde debería haber un agujero o un vacío, y por algo debemos entender cualquier cosa. Lo importante es que allí donde debía haber vacío o

\footnotetext{
${ }^{31}$ Ibidem.

${ }^{32}$ Ibidem.

${ }^{33}$ Ibidem.

${ }^{34}$ J. Lacan, El Seminario, Librol0, La angustia, Buenos Aires, Paidós, 2011.
} 
falta algo se presenta, siempre de repente, desconfigurando la imagen en la que el sujeto sostiene la unidad de su cuerpo. Lo Unheimlich es entonces lo que surge en el lugar donde debería estar la falta, y es experimentado como una presencia de "inquietante extrañeza"35.

¿Cual es entonces la diferencia entre el objeto señuelo, que en la sublimación es elevado a la dignidad de la Cosa, y ese algo que puede colmar la falta dando lugar a la experiencia de lo Unheimlich?

Mientras una estética de lo Unheimlich opera colmando el vacío con una presencia que resulta en una experiencia inquietante, una estética de lo éxtimo ofrece un objeto como señuelo para contornear el vacío de la Cosa, es decir para sostenerla como tal en su extimidad. Se trata, por tanto, de una maniobra para preservar el vacío, pero manteniendo la Cosa a distancia, cubriéndola con velos imaginarios que evocan el vacío sin colmarlo. El arte rupestre en/de la gruta constituye sin duda un exemplum y también la película de Herzog que re-presenta esos objetos sublimatorios paleolíticos, haciendo re-sonar el vacío inaugural del ingreso al orden simbólico.

En ambos casos, lo Unheimlich y lo éxtimo, se trata de ese objeto sin imagen, pura consistencia lógica que Lacan llamó objeto $a$, que hereda de das Ding la extimidad y la relación con el goce y lo real, y al que sólo podemos representarnos como objeto cortado del cuerpo. Para decirlo de modo simple, Lacan concibe el cuerpo como unificado y libidinizado a partir de una imagen virtual que el sujeto encuentra en la mirada del Otro y en la imagen del semejante. Por efecto de esta alienación a su imagen ideal, el cuerpo real queda perdido y poco sabemos de él, salvo cuando algo anda mal. Pero aunque el cuerpo real "no entra" en la imagen, el sujeto tiene una representación imaginaria de él en la que se conjugan tanto la imagen ideal como lo que en ella falta, es decir que hay algo que se escamotea en la imagen, que no es especularizable, que se representa como un pedazo cortado del cuerpo y que al mismo tiempo encausa al deseo por su dimensión de falta. Ese singular objeto es el objeto a. Lo Unheimlich tiene lugar cuando algo se presenta en el lugar de esa falta en la imagen. Más específicamente, el efecto inquietante ocurre cuando este objeto sin imagen $\mathrm{y}$, por tanto, no localizable, aparece de repente en la escena del mundo. Lo que se revela, en definitiva, es esa presencia fuera de la imagen que, sin embargo, es constitutiva de este lugar como ausencia, haciendo vacilar la imagen que sostiene al cuerpo, o convirtiéndola en la imagen extraña del doble. Esta aparición de una presencia in-

\footnotetext{
${ }^{35}$ En la película este registro se pone de manifiesto cuando el silencio de la cueva convoca la presencia de ellos, en el punto en que el latido del propio corazón resuena en el silencio virando hacia la extrañeza. Más tarde vuelve a presentarse como mirada que llena el vacío de la cueva, manisfestándose como sensación de ser observados. Finalmente este registro es convocado con la figura clásica del doble, cuando Herzog nos muestra los cocodrilos albinos en esa especie de pesadilla nuclear contemporánea que añade como epílogo.
} 
quietante hace faltar la falta y convoca la angustia, afecto de lo real, que por lo tanto no es sin objeto, sostiene Lacan.

En cambio, una estética de lo éxtimo, si cabe formularla así, supone un uso del objeto imaginarizado de modo tal de preservar esa ausencia en la imagen que es precisamente lo que sostiene nuestro cuerpo. Entonces, si hay una estética de lo éxtimo, es en tanto concierne al cuerpo, que es el cuerpo del mundo, el cuerpo de la gruta. Lacan señala de entrada que el reverso ineluctable de la imagen especular unificadora es el fantasma del cuerpo fragmentado. Este cuerpo fragmentado remite a la anarquía del cuerpo pulsional, en el que cada zona erógena goza por su cuenta, por así decirlo. Para teorizar este cuerpo pulsional, Lacan traslada el modelo de la vasija de Heidegger al cuerpo, y lo hace reduciendo el vacío abismal de das Ding a múltiples y pequeños agujeros, que son los que resultan del corte que separa al objeto $a$ del cuerpo. Alrededor de este objeto desprendido del cuerpo, la pulsión gira en su perpetua búsqueda de satisfacción, que nunca da con ese objeto faltante por estructura, relanzando el deseo.

Cabe afirmar, pues, de acuerdo a la estética de lo éxtimo según Lacan, que el cuerpo, el cuerpo del mundo, el cuerpo de la gruta, muestra, y de manera ejemplar, en primer lugar, la ausencia de la imagen. En esa ausencia resuena sin duda por lo demás la "ausencia de figura" a la que alude Nancy en "La pintura en la gruta". En segundo lugar, no es posible obviar que el cuerpo, que ese cuerpo, es decir, que el cuerpo así mostrado, aquí el cuerpo en/del arte, muestra en la falta del objeto ideal de Lacan -que es a la par, y sin duda a la par en el corpus hegeliano, objeto de deseo y objeto de pugna- la falta de reconocimiento que Nancy instituye a modo de diagnóstico o conjuro de la razón ilustrada de Occidente que rige no sólo en clave ontológica, sino también estética y política. 